\title{
The use of bicycle workstations to increase physical activity in secondary classrooms
}

\begin{abstract}
BACKGROUND
To date, the majority of interventions have implemented classroom-based physical activity (PA) at the elementary level; however, there is both the potential and need to explore student outcomes at high-school level as well, given that very few studies have incorporated classroom-based PA interventions for adolescents. One exception has been the use of bicycle workstations within secondary classrooms. Using bicycle workstations in lieu of traditional chairs in a high school setting shows promise for enhancing adolescents' physical activity during the school day.
\end{abstract}

\section{PARTICIPANTS AND PROCEDURE}

The present study explored the effects of integrating bicycle workstations into a secondary classroom setting for four months in a sample of 115 adolescents using an A-B-A-B withdrawal design. The study took place in one Advanced Placement English classroom across five groups of students. Physical activity outcomes included average heart rate, and caloric expenditure. Behavioural outcomes included percentage of on-task/off-task behaviour and number of teacher prompts in redirecting off-task behaviour. Feasibility and acceptability data of using the bicycle workstations were also collected.

\section{RESULTS}

Findings showed significant improvements in physical activity as measured by heart rate and caloric expenditure, although heart rate percentage remained in the low intensity range when students were on the bicycle workstations. No effects were found on students' on-task behaviour when using the bicycle workstations. Overall, students found the bikes acceptable to use but noted disadvantages of them as well.

\section{CONCLUSIONS}

Using bicycle workstations in high-school settings appears promising for enhancing low-intensity physical activity among adolescents. The limitations of the present study and implications for physical activity interventions in secondary schools are discussed.

KEY WORDS

FitDesk $^{\circledast}$; stationary cycling; school; workstation

ORGANISATION - 1: University of Kentucky, Lexington, USA 2: University of Miami, Coral Gables, USA

AUthors' Contributions - A: Study design - B: Data collection - C: Statistical analysis - D: Data interpretation .

E: Manuscript preparation · F: Literature search · G: Funds collection

CORRESPONDING AUthor - Alicia Fedewa, Ph.D., University of Kentucky, 236 Dickey Hall, 40506 Lexington, USA, e-mail: alicia.fedewa@uky.edu

to Cite this ARticle - Fedewa, A., Cornelius, C., \& Ahn, S. (2018). The use of bicycle workstations to increase physical activity in secondary classrooms. Health Psychology Report, 6(1), 60-74. doi: https://doi.org/10.5114/hpr.2018.71211

RECEIVED 28.02.2017 · REVIEWED 12.05.2017 · ACCEPTED 06.06.2017 · PUBLISHED 14.11.2017 


\section{BACKGROUND}

\section{THE USE OF BICYCLE WORKSTATIONS TO INCREASE PHYSICAL ACTIVITY IN SECONDARY CLASSROOMS}

Over $30 \%$ of children in the US are overweight or obese with rates continuing to climb (Burkhalter \& Hillman, 2011; Centres for Disease Control and Prevention [CDC], 2015). Moreover, childhood obesity has more than doubled in youths and quadrupled in adolescents compared to only three decades ago (CDC, 2015). Obese youths are at elevated risk for cardiovascular diseases such as high cholesterol and blood pressure as well as diabetes, asthma, arthritis, bone and joint issues, sleep apnoea, and social and emotional problems like stigmatisation and poor self-esteem (CDC, 2017). Obese adolescents specifically are at an increased risk for prediabetes (CDC, 2011; CDC, 2017). Obesity, in part, can be attributed to the fewer than one third of children who meet $\mathrm{CDC}$ daily requirements of 60 minutes of accumulated moderate-vigorous physical activity (MVPA; CDC, 2015; Ekeland et al., 2012; WHO, 2011). Furthermore, research has documented that this proportion of youths meeting $\mathrm{CDC}$ requirements declines as children mature and older adolescents stop participating in organised, recreational sports (Johnson \& Taliaferro, 2011; Mitchell et al., 2012). In fact, only an estimated $25 \%$ of high school students reach CDC daily requirements (CDC, 2015). As such, the lack of childhood physical activity, particularly among adolescents, is a consequential concern.

\section{EFFECT OF ACTIVITY ON STUDENT COGNITION AND ACHIEVEMENT}

The health benefits of physical activity (PA) are well established (CDC, 2015). Exercise is pertinent to the physical health of children and, if started early in life, cascades into a multitude of health benefits, including reduced risk for chronic diseases, coronary heart disease, type-2 diabetes, obesity, cancer, and arthritis (Carson et al., 2014; Hills, Dengal, \& Lubans, 2015; Iannotti, Kogan, Janssen, \& Boyce, 2009). Most recently, physical activity has also reflected large, stable and independent links to areas of cognitive functioning in youths (Davis, Tkacs, Tomporowski, \& Bustamente, 2015). Research suggests that physical fitness, short bouts of PA, and more sustained PA interventions are advantageous to school-age youths' cognitive functioning (Donnelly et al., 2016; Mura, Vellante, Nardi, Machado, \& Carta, 2015; Verburgh, Konigs, Scherder, \& Ossterlaan, 2013). Selective attention, information processing, executive functioning, and memory performance are the most studied outcomes when measuring the effect of physical activity on children's cognition. Given that these cognitive outcomes are the skills necessary for successful academic performance (Donnelly et al., 2016), the benefits of physical activity interventions would likely generalise to school and classroom settings.

Because schools serve approximately 56 million youths each year (National Centre for Education Statistics, 2016) and children spend approximately 30 hours each week at school, schools are a logical platform to address children's lack of physical activity (Dobbins, Husson, DeCorby, \& LaRocca, 2013; Kriemler et al., 2011). Schools offer an opportunity to reach a wide range of children and also target those most in need, while also presenting the possibility of adding social support for engaging in physical activity (Hamilton, Warner, \& Schwarzer, 2016; Salvy et al., 2009). Moreover, findings consistently reveal a relationship between school-based physical activity and academic gains, including: increased academic achievement; higher outcomes in math, reading and English; and improved cognition and concentration (CDC, 2015; Rasberry et al., 2011). Although schools are often constrained by budgets and curriculum requirements (Rasberry et al., 2011), no PA studies to date have shown that time allotted to school-based physical activity detracts from academic performance (Babey, Wu, \& Cohen, 2014; Donnelly et al., 2016; Rasberry et al., 2011). As such, finding opportunities for educators to embed PA supports the supposition that enhance health and academic outcomes for youths, which are both feasible and acceptable for educators, is paramount to a sustainable intervention.

\section{EFFECT OF ACTIVITY FOR ON-TASK BEHAVIOUR}

The effect of exercise on attention-to-task is another area that has been explored within the classroom (Janssen et al., 2014; Mahar, 2011; Webster, Wadsworth, \& Robinson, 2015). Physical activity has been neurologically linked to increases in executive functioning; it has the capacity to promote neural proliferation and to shape synaptic transmission in manners that alter thinking, decision-making, and behaviour mechanisms related to the amount of attention given to a specific cognitive task (Donnelly et al., 2016; Hillman, Buck, Themanson, Pontifex, \& Castelli, 2009; Pontifex, Scudder, Drollette, \& Hillman, 2012). Mura et al. (2015) found in a systematic review of 31 studies showing that embedding PA into the classroom may have positive links to student attention and concentration. Independent studies have mirrored these results. For example, Ma et al. (2014) explored the impact of FUNtervals (i.e. brief high-intensity intervals following an interactive storyline) on third- through fifth-grade student attention. 
Alicia Fedewa, Colleen Cornelius, Soyeon Ahn
Study findings showed that children decreased their errors on the $\mathrm{d} 2$ assessment after FUNtervals than when compared to the control group. Similarly, ontask behaviour within the classroom has also been measured after bouts of aerobic activity have been integrated into the curriculum. Mahar et al. (2006) examined the impact of 10 minutes of daily classroom-based physical activity (i.e. "energisers") on third- and fourth-grade students and found that the intervention increased children's PA levels as well as on-task behaviour. Whitt-Glover, Ham, and Yancey (2011) supported these results, finding an $11 \%$ time on-task increase for elementary students who participated in Instant Recess (i.e. 10-minute PA breaks set to music) in the classroom. Thus, reviews and independent studies suggest a multitude of benefits for classroom-based physical activity for children's cognitive and behavioural outcomes.

\section{INCORPORATING ADDITIONAL ACTIVITY WITHIN THE SCHOOL DAY}

Four typical ways in which PA has been effectively incorporated into the school day include before- and after-school opportunities as well as extending the school day to allow for 60 minutes of PE and in-class PA opportunities (Babey et al., 2014; Dobbins et al., 2013). Though all are plausible options, staffing, cost, participation, and transportation become issues for all but classroom-based PA (Babey et al., 2014; Bassett et al., 2013). Exercise within the classroom reflects much promise, as it reaches the most students and is cost-effective (Babey et al., 2014; Bassett et al., 2013). Classroom PA can support weight loss, increase physical fitness, improve motivation in class and increase academic achievement (Barr-Anderson et al., 2011; Carlson et al., 2015; Donnelly \& Lambourne, 2011; Kibbe et al., 2011). For example, Erwin, Fedewa, and Ahn (2013) found that a 20-week intervention for third-grade students, which provided at least 20 minutes of physically-active lessons, reflected significantly higher reading fluency and mathematics outcomes on a validated curriculum-based measure. Similarly, Have et al. (2016) noted that integrating physical activity into classroom math lessons improved math achievement for first-grade students ( $n=505)$, while also increasing their fitness, cognition, and overall body mass index (BMI). Other findings support these results (Bailey \& DiPerna, 2015; Howie, Schatz, \& Pate, 2015; Kibbe et al., 2011).

\section{AIM OF THE STUDY}

To date, the majority of interventions have implemented classroom-based PA at the elementary level; however, there is both potential (Tarp et al., 2016;
Kantomaaa et al., 2013; Shin \& So, 2012) and a need (Johnson \& Taliaferro, 2011; Mitchell et al., 2012) to explore student outcomes at the high school level, also given that very few studies have incorporated classroom-based PA interventions for adolescents. One exception has been the use of bicycle workstations within secondary classrooms (Fedewa, Abel, \& Erwin, 2017). Using bicycle workstations in lieu of traditional chairs in a high school setting showed promise for enhancing adolescents' physical activity during the school day. However, the one study to date using these bicycle workstations in the classroom was based on a small sample within an alternative high school and did not assess student on-task behaviour.

Although limited research exists on the use of bicycle workstations within classrooms, based on the prior study by Fedewa, Abel, and Erwin (2017), we hypothesise that students who have access to bicycle workstations will accrue additional low to moderate physical activity during the school day. Furthermore, the present study will examine the relationship between classroom-based physical activity and adolescent on-task engagement using a larger adolescent sample. Given the prior research on the effects of physical activity for student's attention, we hypothesise that adolescents would demonstrate more ontask engagement during instruction while using the bicycle workstations. An additional question was the extent to which these bikes are acceptable to the students using them in the classroom, given that the feasibility and acceptability of bicycle workstations in school settings has not been well established.

\section{PARTICIPANTS AND PROCEDURE}

\section{PARTICIPANTS}

The study took place in a secondary school setting in an urban, Southeastern State in the United States. One English classroom within the high school participated in the study. The English classroom served five different groups of students during the school day ( $n=115)$. However, only four of these groups were included because the fifth group was a performing arts English course wherein students were not seated for most of the period. Thus, to maintain consistency across classrooms in terms of instructional demands, only four English classrooms were used in the present study. After full approval from the University Institutional Review Board and internal funding from a University grant (Centre for Clinical and Translational Sciences, University of Kentucky), parental consent forms were sent home to the remaining 92 students' parents. Out of the 92 students, parental consent and student assent were obtained from 80 students ( $87 \%$ consent participation rate). The 


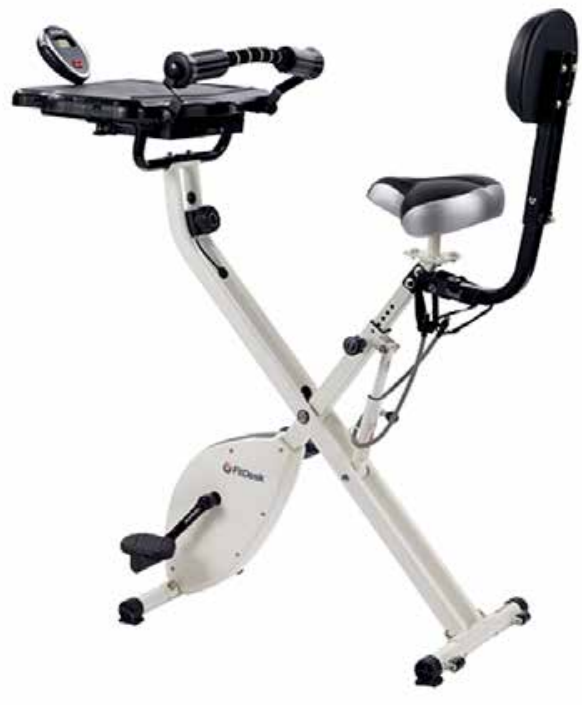

Figure 1. FitDesk bicycle workstation.

mean age of the 80 students in the sample was 16.06 years $(\min =16, \max =17)$ and $47 \%$ were female.

\section{PROCEDURE}

One English classroom housed all 12 bicycle workstations (FitDesk ${ }^{\circledR}$; see Figure 1) in addition to their regular desks within the classroom for 16 weeks. Given that each class period was exactly 60 minutes long and there were approximately 20 students in each class that could ride the bikes, students would typically spend approximately 20 minutes on the bikes and then switch with another student so that each student would spend approximately half of the class period on the bike. Providing each student with 20 minutes on the bikes allowed for transition time and, when applicable, additional time to put on the heart rate monitors and record their data on the hard copy logs described in further detail below.

The FitDesk ${ }^{\circledR}$ bicycle workstations were equipped with a screen that displayed calories, miles, activity time, and resistance level. Students were able to turn their resistance level and increase the workload (i.e. intensity of the exercise) on a scale of one (low) to eight (high). The seat and angle of the desk could be adjusted for ease of use, and the FitDesk ${ }^{\circledR}$ had arm rests and a back support that could be removed.

In addition to baseline data collection, data was collected in three additional waves following an A-BA-B design. Each wave of data collection lasted for two weeks (10 school days). Baseline data collection and the additional withdrawal phase consisted of equipping students with heart rate monitors while seated in their traditional chairs. The average heart rate and total calories of each student was collected for 20 minutes of the class period (the time each student would ride the bike) and recorded on an activity log that each student kept for the duration of the study. During the intervention phase, students would record their heart rates and total calories as well as the additional data provided from the bicycle workstations (miles, resistance level, time) for 20 minutes while on the bicycle workstations.

\section{INSTRUMENTS}

Bicycle desks

Physical activity. Participants were asked to wear heart rate monitors (Polar F4) around their chest during the data collection periods (two weeks at four different time points). Four student researchers trained by the lead researchers in attaching and monitoring the fidelity of the heart rate monitor wear were present during each day of the data collection periods (40 school days in total). The student researchers ensured that students were wearing their heart rate monitors, and during the times data was being recorded on the bicycle workstations they logged the data from their FitDesk ${ }^{\circledast}$ screens. The data from the screens included miles, resistance, and time that the students recorded on with pencil and paper logs.

Teacher Prompts. The number of teacher prompts to pedal (when applicable) and to redirect student behaviour were coded during each observation (10 observations per classroom for each wave; 40 total observations). These behavioural observations were conducted using Momentary Time Sampling (MTS; see Fedewa \& Erwin, 2011; Rapp et al., 2008) in which every 30 seconds the observer would code whether the teacher prompted students to redirect their behaviour or to pedal. Any teacher request directed at student misbehaviour was coded as a prompt, as was any teacher encouragement to pedal or exercise while on the bicycle workstations. A stopwatch was used to track the 30-second time interval, and observers would mark their observations on designated spreadsheets assigned for each child participant. Following that of previous research studies (Fedewa \& Erwin, 2011), 30-second increments of MTS were selected because it has been shown to reduce the number of false positives for duration events (Rapp et al., 2008). Observations using this methodology have also proven to be more valid and reliable across observers.

Student Behaviour. During each movement break, observers coded two different student behaviours: on-task and off-task. Observers used the same momentary time sampling method as was used for the teacher prompt observations: every $30 \mathrm{sec}-$ onds, the researcher would code whether these behaviours were occurring during the respective interval. The frequency of these behaviours was summed and divided by the interval time, resulting in a percentage of on-task/off-task behaviour. These percent- 
ages were then compared for students while on and off the bicycle workstations.

Feasibility. Each of the four classrooms completed a quantitative survey, which included room for open-ended suggestions and improvements in using the FitDesk ${ }^{\circledR}$ within a classroom setting (Fedewa, Erwin, \& Abel, in press). This questionnaire included 11 items on a Likert scale of 1 (definitely false) to 5 (definitely true). Items assessed student enjoyment, perception of whether the bike desks helped with at-

Alicia Fedewa, Colleen Cornelius, Soyeon Ahn tention and behaviour, and the comfort/logistics of the bike. Example items included "I enjoyed riding the bike during class," "I could pay more attention riding the bicycle than when I was sitting in a chair," and "I preferred sitting on the bike during class rather than in a chair."

FitDesk $^{\circledast}$. For research questions 1 and 2, two sets of multilevel analysis (known as Hierarchical Linear Modelling [HLM]) were conducted using Mplus in order to examine the effect of bikes on each student outcome: physical activity and on-task behaviour. The first multilevel analysis predicted each of the student outcomes using two dummy variables, which were (1) a dummy variable indicating the treatment effect ( 0 = baseline, $1=$ treatment) and (2) a dummy variable indicating the order effect $(0=$ the first $\mathrm{AB}$ pair and 1 = the second $A B$ pair), and their interaction between treatment and order effects. All fixed and random effects were estimated and their significances were tested.

The second multilevel analysis was to predict each of the student outcomes based on step coding. Step coding was used to examine the significance of changes between two pairs of phases. In the multilevel analysis on student physical activity, three effects were used to examine the significance of changes from A1 (the first A phase) to B1 (the first B phase), from $\mathrm{B} 1$ to $\mathrm{A} 2$ (the second $\mathrm{A}$ phase), and from $\mathrm{A} 2$ to $\mathrm{B} 2$ (the second $\mathrm{B}$ phase). In the multilevel analysis on student on-task behaviours, two effects were used to examine the significance of changes from B1 to A2 (the second A phase) and from A2 to B2 (the second $B$ phase) because no baseline measure (A1) was available in the first phase. All fixed and random effects were estimated and their significances were tested.

For research question 3, an exploratory factor analysis using principal axis factoring was performed to extract principal factors from 11 survey items, in which each factor with an eigenvalue of one was retained. Each factor was interpreted based on an inspection of pattern matrix after factor rotation using direct oblimin and qualitative analysis of each item. A measure of internal consistency was examined for each factor based on a Cronbach $\alpha$ value. Then, descriptive statistics of the composite scale score by averaging item responses for each factor was described to illustrate the student's level of acceptance of using the FitDesk ${ }^{\circledR}$ workstation.

\section{RESULTS}

\section{DESCRIPTIVE STATISTICS}

Table 1 displays descriptive statistics for physical activity variables including average activity, average miles riding a bike, average calorie consumption, average percentage $\mathrm{HR}$, and average $\mathrm{HR}$ by phase. Table 2 displays descriptive statistics for student ontask behaviours by phase.

\section{THE EFFECT OF THE BIKES ON STUDENT PHYSICAL ACTIVITY}

Table 3 and Table 4 display results from two multilevel analyses on each physical activity outcome - one using dummy coding (Table 3) and the other using step coding (Table 4).

The effect of the bikes on average heart rate. The results are the first four columns in Table 3, showing the significance of fixed and random effects from multilevel analysis with dummy coding. As shown in Table 3, the effect of riding bikes was found to be statistically significant $\left(\hat{\beta}_{10}=15.81, S E=1.59, t=9.96\right.$, $p<.001$; $95 \%$ CI: 12.70 to 18.92 ), indicating that students tend to have higher average heart rates during the intervention phase than during the baseline phase. Although significant, the level of intensity remained low across intervention phases, averaging 39\% maximum heart rate in the first phase and $26 \%$ maximum heart rate in the second intervention phase. The order effect was not statistically significant $\hat{\beta}_{20}=3.44, S E=1.94, t=1.77, p=.080 ; 95 \% \mathrm{CI}:-0.37$ to 7.24), showing that on average heart rates were similar between the first $\mathrm{AB}$ pair and the second $\mathrm{AB}$ pair. However, the treatment effect on average heart rate was found to be more effective in the first $A B$ pair than in the second $A B$ pair, as shown in the significant interaction between treatment and order $\left(\hat{\beta}_{30}=-7.57, S E=2.61, t=3.04, p=.002 ; 95 \% \mathrm{CI}:-12.76\right.$ to -2.37$)$. In addition, female students had significantly higher average heart rates than male students $\left(\hat{\beta}_{01}=7.92, S E=2.61, t=3.04, p=.002 ; 95 \% \mathrm{CI}: 2.81\right.$ to 13.03). Only one of the variance components was significant, suggesting that the average heart rate varied across male students $\left(\hat{\tau}_{00}=56.10, p<.001\right)$. The remaining variance components were not statistically significant.

The results are the first four columns in Table 4, showing the significance of fixed and random effects from multilevel analysis with step coding. As shown in Table 4, changes in average heart rate were all statistically significant for the following pairs of four distinct phases: (1) A1 (the first baseline [A] phase) to $\mathrm{B} 1$ (the first treatment [B] phase), (2) B1 to A2 (the second baseline [A] phase), and (3) A2 to B2 (the second treatment $[\mathrm{B}]$ phase). For the average student, 
Table 1

Descriptive statistics for physical activity variables by phase

\begin{tabular}{|c|c|c|c|c|c|}
\hline Phase & Physical activity variable & $\min$ & $\max$ & $M$ & $S D$ \\
\hline \multirow[t]{5}{*}{$\mathrm{A} 1$} & Average activity & 18.00 & 25.00 & 21.17 & 1.62 \\
\hline & Average miles riding bike & & & & \\
\hline & Average calorie expenditure & 20.75 & 72.00 & 36.27 & 9.56 \\
\hline & Average percentage HR & 0.00 & 48.53 & 35.08 & 10.61 \\
\hline & Average HR & 53.25 & 99.00 & 76.34 & 11.30 \\
\hline \multirow[t]{5}{*}{ B1 } & Average activity & 9.00 & 28.33 & 20.25 & 2.94 \\
\hline & Average miles riding bike & 0.42 & 6.55 & 3.36 & 1.49 \\
\hline & Average calorie expenditure & 28.00 & 92.66 & 52.94 & 16.57 \\
\hline & Average percentage $\mathrm{HR}$ & 0.00 & 59.20 & 39.04 & 16.88 \\
\hline & Average HR & 72.40 & 120.77 & 92.91 & 11.21 \\
\hline \multirow[t]{5}{*}{ A2 } & Average activity & 19.28 & 38.42 & 24.72 & 5.29 \\
\hline & Average miles riding bike & 0.63 & 5.73 & 2.50 & 1.53 \\
\hline & Average calorie expenditure & 28.13 & 265.00 & 63.83 & 51.41 \\
\hline & Average percentage HR & 0.00 & 50.56 & 20.11 & 20.34 \\
\hline & Average HR & 61.10 & 103.14 & 80.41 & 12.00 \\
\hline \multirow[t]{5}{*}{ B2 } & Average activity & 15.60 & 37.50 & 21.37 & 3.98 \\
\hline & Average miles riding bike & 0.63 & 6.49 & 2.66 & 1.56 \\
\hline & Average calorie expenditure & 10.00 & 115.31 & 51.34 & 21.67 \\
\hline & Average percentage HR & 0.00 & 51.75 & 25.42 & 21.69 \\
\hline & Average HR & 69.62 & 105.57 & 87.63 & 10.55 \\
\hline
\end{tabular}

Table 2

Descriptive statistics for student on-task variables by phase

\begin{tabular}{lcrrrr}
\hline Phase & Student on-task behaviours & $\min$ & $\max$ & M & \multicolumn{2}{c}{$S D$} \\
\hline B1 & Bike on-task behaviours & 87.03 & 98.02 & 94.34 & 4.22 \\
& Chair on-task behaviours & 90.32 & 98.00 & 94.69 & 3.15 \\
& Average teacher on-task prompts & 0.00 & 1.66 & 0.61 & 0.59 \\
Average teacher exercise prompts & 0.00 & 0.00 & 0.00 & 0.00 \\
A2 & Bike on-task behaviours & 76.25 & 95.35 & 87.86 & 6.22 \\
& Chair on-task behaviours & 80.00 & 98.33 & 91.94 & 6.20 \\
& Average teacher on-task prompts & 0.00 & 0.75 & 0.29 & 0.27 \\
Average teacher exercise prompts & 0.00 & 0.25 & 0.12 & 0.13 \\
& Bike on-task behaviours & 66.70 & 97.50 & 89.72 & 10.56 \\
& Cherair on-task behaviours & 90.00 & 98.80 & 94.12 & 3.03
\end{tabular}


Table 3

Results from multilevel analysis on physical activity outcomes using dummy coding

\begin{tabular}{lcccccccc}
\hline Effect & \multicolumn{7}{c}{ Physical activity outcome } \\
\cline { 2 - 9 } & \multicolumn{7}{c}{ Average heart rate } & \multicolumn{7}{c}{ Average calorie consumption } \\
\hline Fixed effect & $b$ & $S E$ & $t$ & $p$ & $b$ & $S E$ & $t$ & $p$ \\
\hline Intercept & 73.22 & 1.87 & 39.15 & $<.001$ & 34.33 & 1.79 & 19.13 & $<.001$ \\
Treatment & 15.81 & 1.59 & 9.96 & $<.001$ & 16.68 & 2.39 & 6.99 & $<.001$ \\
AB pair & 3.44 & 1.94 & 1.77 & .080 & 23.66 & 8.14 & 2.91 & .005 \\
Treatment * AB & -7.57 & 2.66 & -2.86 & .004 & -20.46 & 6.16 & -3.32 & .001 \\
Female & 7.92 & 2.61 & 3.04 & .002 & 4.91 & 2.77 & 1.78 & .080 \\
Random effect & $\hat{\tau}$ & $S E$ & $z$ & $p$ & $\hat{\tau}$ & $S E$ & $z$ & $p$ \\
Intercept & 56.10 & 16.23 & 3.46 & .001 & 48.30 & 21 & 2.30 & .020 \\
Treatment & 0.54 & 17.26 & 0.03 & .980 & 149.32 & 51.87 & 2.88 & .004 \\
AB pair & 0.53 & 18.12 & 0.03 & .980 & 1958.45 & 503.53 & 3.89 & $<.001$ \\
Treatment ${ }^{*} \mathrm{AB}$ & 0.32 & 24.49 & 0.01 & .990 & 547.38 & 225.96 & 2.42 & .020 \\
Level1 & 50.87 & 11.33 & 4.49 & $<.001$ & 41.43 & 22.43 & 1.85 & .070 \\
\hline
\end{tabular}

Table 4

Results from multilevel analysis on physical activity outcomes using step coding

\begin{tabular}{lcccccccc}
\hline \multirow{2}{*}{ Effect } & \multicolumn{7}{c}{ Physical activity outcome } \\
\cline { 2 - 9 } & \multicolumn{7}{c}{ Average heart rate } & \multicolumn{7}{c}{ Average calorie consumption } \\
\hline Fixed effect & $b$ & $S E$ & $t$ & $p$ & $b$ & $S E$ & $t$ & $p$ \\
\hline Intercept & 72.71 & 1.81 & 40.22 & $<.001$ & 34.29 & 1.77 & 19.48 & $<.001$ \\
A1 to B1 & 16.35 & 1.61 & 10.15 & $<.001$ & 16.49 & 2.40 & 6.88 & $<.001$ \\
B1 to A2 & -10.87 & 1.85 & -5.89 & $<.001$ & 7.95 & 8.05 & 0.99 & .320 \\
A2 to B2 & 5.91 & 2.01 & 2.94 & .003 & -5.08 & 5.77 & -0.88 & .380 \\
Female & 8.21 & 2.61 & 3.14 & .002 & 5.10 & 2.75 & 1.86 & .060 \\
Random effect & $\hat{\tau}$ & $S E$ & $z$ & $p$ & $\hat{\tau}$ & $S E$ & $z$ & $p$ \\
Intercept & 52.61 & 16.03 & 3.28 & .001 & 51.85 & 23.24 & 2.23 & .030 \\
A1 to B1 & 15.31 & 17.11 & 0.89 & .370 & 165.96 & 54.49 & 3.05 & .002 \\
B1 to A2 & 0.32 & 16.97 & 0.02 & .990 & 1912.50 & 492.31 & 3.89 & $<.001$ \\
A2 to B2 & 0.43 & 22.14 & 0.02 & .990 & 556.41 & 204.15 & 2.73 & .006 \\
Level1 & 45.80 & 10.35 & 4.43 & $<.001$ & 33.47 & 23.31 & 1.44 & .150 \\
\hline
\end{tabular}

the change from the first baseline phase (A1) to the first treatment phase (B1) was significant, showing an increase in average heart rate from A1 to B1 $\left(\hat{\beta}_{10}=16.35, S E=1.61, t=10.15, p<.001 ; 95 \% \mathrm{CI}: 13.19\right.$ to 19.51). Average heart rate dropped from B1 to A2 $\left(\hat{\beta}_{20}=-10.87, S E=1.85, t=-5389, p<.001 ; 95 \% \mathrm{CI}\right.$ : -14.49 to -7.25$)$ and then increased from A2 to B2 $\left(\hat{\beta}_{10}=5.91, S E=2.01, t=2.94, p=.003 ; 95 \% \mathrm{CI}: 1.97\right.$ to 9.85$)$. Only one of the variance components was significant, suggesting that average heart rate varied across male students $\left(\hat{\tau}_{00}=52.61, p<.001\right)$. The remaining variance components were not statistically significant.

The effect of the bikes on average calorie expenditure. The results are the last four columns in Table 3, showing the significance of fixed and random effects from a multilevel analysis with dummy coding. As shown in Table 3, the effect of riding bikes was found to be statistically significant $\left(\hat{\beta}_{10}=16.68, S E=2.39, t=6.99, p<.001 ; 95 \% \mathrm{CI}:\right.$ 
12.00 to 21.36), indicating that students tend to burn more calories during the intervention phase than during the baseline phase. The order effect was statistically significant $\left(\hat{\beta}_{20}=23.66, S E=8.14, t=2.91\right.$, $p=.004$; $95 \%$ CI: 7.70 to 39.62 ), showing that on average calorie expenditures were similar between the first $\mathrm{AB}$ pair and the second $\mathrm{AB}$ pair. Furthermore, the treatment effect on average calorie expenditure was found to be more effective in the first $A B$ pair than in the second $A B$ pair, as shown in the significant interaction between treatment and order $\left(\hat{\beta}_{20}=-20.46, S E=6.16, t=-3.32, p<.001 ; 95 \% \mathrm{CI}\right.$ : -32.54 to -8.39$)$. The random effects show that the intercept $\left(\hat{\tau}_{00}=48.30, p=.020\right)$, the treatment effect $\left(\hat{\tau}_{00}=149.32, p=.004\right)$, the order effect $\left(\hat{\tau}_{00}=1958.46\right.$, $p<.001)$, and the interaction effect between order and treatment $\left(\hat{\tau}_{00}=547.38, p=.020\right)$ all vary significantly across individuals.

The results are the last four columns of Table 4 , showing the significance of fixed and random effects from a multilevel analysis with step coding. As shown in Table 4, the change in average calorie expenditure was only statistically significant from A1 (the first baseline [A] phase) to B1 (the first treatment [B] phase), showing a significant increase in average calories burned from A1 to B1 $\left(\hat{\beta}_{10}=16.49, S E=2.40\right.$, $t=6.88, p<.001$; 95\% CI: 11.80 to 21.19 ). No significant changes in average calorie expenditure were found from B1 to A2 $\left(\hat{\beta}_{20}=7.95, S E=8.05, t=0.99\right.$, $p=.330 ; 95 \% \mathrm{CI}:-7.82$ to 23.72$)$ or from $\mathrm{A} 2$ to $\mathrm{B} 2$ $\left(\hat{\beta}_{10}=-5.08, S E=5.77, t=-0.88, p=.380 ; 95 \% \mathrm{CI}:-16.39\right.$ to 6.23$)$. The random effects show that the intercept $\left(\hat{\tau}_{00}=51.85, p=.030\right)$, the A1-B1 effects $\left(\hat{\tau}_{00}=165.96\right.$, $p=.002)$, the B1-A2 effects $\left(\hat{\tau}_{00}=1912.50, p<.001\right)$, and
A2-B2 effects $\left(\hat{\tau}_{00}=556.41, p=.006\right)$ all vary significantly across individuals.

\section{THE EFFECT OF THE BIKES ON STUDENT ON-TASK BEHAVIOUR}

Table 5 and 6 display results from two multilevel analyses on four students' on-task behaviours, including (1) bike on-task behaviours, (2) chair on-task behaviours, (3) average teacher on-task prompts, and (4) average teacher exercise prompts - one using dummy coding (Table 5) and the other using step coding (Table 6). As shown in Table 5, the treatment effects were not significant in any of the students' on-task behaviours. None of the random variance components were significant. As shown in Table 6, changes in students' on-task behaviours were all similar in all pairs of phases: (1) B1 (the first treatment [B] phase) to A2 (the second baseline [A] phase), and (2) A2 to B2 (the second treatment [B] phase). None of the random variance components were significant.

\section{STUDENT ACCEPTANCE OF BICYCLE WORKSTATIONS}

Using an exploratory factor analysis with direct oblimin rotation, three principal factors were extracted from 11 survey items based on a Kaier rule. Based on the pattern matrix shown in Table 7 and item characteristics, three factors were interpreted as follows: Factor 1 - Academic Benefits from the Bike (e.g. "Riding a bicycle in class helped me listen

Table 5

Results from multilevel analysis on student on-task behaviours using step coding

\begin{tabular}{lcccccccc}
\hline & \multicolumn{7}{c}{ Student on-task behaviours } \\
\cline { 2 - 10 } & \multicolumn{2}{c}{ On the bike } & On the chair & $\begin{array}{c}\text { Teacher on-task } \\
\text { prompts }\end{array}$ & $\begin{array}{c}\text { Teacher exercise } \\
\text { prompts }\end{array}$ \\
\hline Fixed effect & $b$ & $S E$ & $b$ & $S E$ & $b$ & $S E$ & $b$ & $S E$ \\
\hline Intercept & $91.04^{* *}$ & 11.22 & $92.83^{* *}$ & 6.69 & 0.30 & 0.72 & 0.04 & 0.14 \\
Session & 1.26 & 4.40 & 0.73 & 2.60 & 0.13 & 0.28 & -0.02 & 0.05 \\
Treatment & -2.89 & 11.49 & -1.38 & 6.79 & -0.03 & 0.73 & 0.09 & 0.14 \\
Session *treatment & -0.99 & 4.51 & -0.09 & 2.64 & -0.11 & 0.29 & -0.007 & 0.05 \\
Random effect & $\hat{\tau}$ & $S E$ & $\hat{\tau}$ & $S E$ & $\hat{\tau}$ & $S E$ & $\hat{\tau}$ & $S E$ \\
Intercept & 0.04 & 3.61 & 3.64 & 7.14 & $<.001$ & 0.01 & $<.001$ & 0.001 \\
Session & 0.006 & 0.54 & 0.004 & 2.11 & $<.001$ & 0.01 & $<.001$ & $<.001$ \\
Treatment & 0.23 & 16.19 & 0.04 & 7.84 & $<.001$ & 0.01 & 0.001 & 0.001 \\
Session *treatment & 1.53 & 2.18 & 0.04 & 1.38 & $<.001^{* *}<.001$ & $<.001$ & $<.001$ \\
Level1 & $38.59^{* *}$ & 11.90 & 12.68 & 7.67 & 0.15 & 0.05 & $0.006^{* *}$ & 0.002 \\
\hline Note. ** $p<.01 ;{ }^{*} p<.05$. & & & & & & & &
\end{tabular}


Table 6

Results from multilevel analysis on student on-task behaviours using step coding

\begin{tabular}{|c|c|c|c|c|c|c|c|c|}
\hline \multirow[b]{3}{*}{ Fixed effect } & \multicolumn{8}{|c|}{ Outcome } \\
\hline & \multicolumn{2}{|c|}{$\begin{array}{l}\text { On-task while } \\
\text { bike }\end{array}$} & \multicolumn{2}{|c|}{$\begin{array}{c}\text { On-task while } \\
\text { chair }\end{array}$} & \multicolumn{2}{|c|}{$\begin{array}{c}\text { Teacher on-task } \\
\text { prompts }\end{array}$} & \multicolumn{2}{|c|}{ Exercise } \\
\hline & $b$ & $S E$ & $b$ & $S E$ & $b$ & $S E$ & $b$ & $S E$ \\
\hline Intercept & $88.73^{* *}$ & 2.71 & $91.47^{* *}$ & 1.74 & 0.24 & 0.16 & $0.12^{* *}$ & 0.03 \\
\hline Session & 0.30 & 2.78 & 0.88 & 1.48 & 0.11 & 0.16 & -0.01 & 0.03 \\
\hline B1 to $A 2$ & 4.22 & 6.59 & 1.02 & 3.45 & 0.11 & 0.37 & -0.10 & 0.08 \\
\hline $\mathrm{A} 2$ to $\mathrm{B} 2$ & -4.59 & 6.77 & -2.32 & 3.45 & -0.47 & 0.37 & 0.04 & 0.08 \\
\hline Random effect & $\hat{\tau}$ & $S E$ & $\hat{\tau}$ & $S E$ & $\hat{\tau}$ & $S E$ & $\hat{\tau}$ & $S E$ \\
\hline Intercept & 0.01 & 5.20 & 3.54 & 4.15 & $<.001$ & 0.01 & $<.001$ & 0.001 \\
\hline Session & 0.003 & 2.23 & 0.003 & 1.20 & $<.001$ & 0.008 & $<.001$ & $<.001$ \\
\hline B1 to $A 2$ & 0.02 & 7.76 & 0.02 & 6.64 & $<.001$ & 0.004 & $<.001$ & $<.001$ \\
\hline $\mathrm{A} 2$ to $\mathrm{B} 2$ & 16.94 & 36.77 & 0.11 & 16.83 & $<.001$ & 0.01 & $<.001^{* *}$ & $<.001$ \\
\hline Level1 & $44.13^{* *}$ & 14.24 & $12.77^{* *}$ & 4.32 & $0.15^{* *}$ & 0.04 & $0.006^{* *}$ & 0.002 \\
\hline
\end{tabular}

Table 7

Pattern and structural matrix

\begin{tabular}{lcccccc}
\hline \multirow{2}{*}{ Items } & \multicolumn{3}{c}{ Pattern matrix } & \multicolumn{3}{c}{ Structural matrix } \\
\cline { 2 - 7 } & Factor 1 & Factor 2 & Factor 3 & Factor 1 & Factor 2 & Factor 3 \\
\hline Q7 & 1.024 & -0.230 & -0.063 & 0.891 & 0.268 & 0.107 \\
Q8 & 0.708 & 0.056 & 0.144 & 0.772 & 0.468 & 0.339 \\
Q6 & 0.70 & 0.094 & 0.050 & 0.761 & 0.469 & 0.257 \\
Q3 & 0.541 & 0.361 & -0.216 & 0.691 & 0.611 & 0.422 \\
Q9 & 0.496 & 0.288 & 0.196 & 0.672 & 0.558 & 0.048 \\
Q1 & -0.064 & 0.893 & -0.032 & 0.382 & 0.849 & 0.275 \\
Q2 & 0.042 & 0.742 & 0.127 & 0.745 & 0.816 & 0.444 \\
Q4 & 0.433 & 0.545 & 0.140 & 0.451 & 0.809 & 0.406 \\
Q5 & 0.322 & 0.393 & 0.294 & 0.595 & 0.663 & 0.516 \\
Reverse-coded Q11 & -0.006 & -0.084 & 0.669 & 0.303 & 0.482 & 0.726 \\
Reverse-coded Q10 & 0.025 & 0.240 & 0.632 & 0.117 & 0.156 & 0.637 \\
\hline
\end{tabular}

Note. Direct oblimin was used for rotation.

to the teacher") explained by Q1, Q2, Q4, and Q5); Factor 2 - Enjoyment of the Bike (e.g. "I preferred sitting on the bike during class than sitting in a chair") explained by Q3, Q6, Q7, Q8, and Q9; and Factor 3 - Shortcomings of the Bike (e.g. "It was hard to listen to the teacher when riding the bike in class") explained by reverse coded Q10 and reverse coded Q11. All three factors explained $63.95 \%$ of variations in all 11 items, with $47.91 \%$ by factor 1: Academic Benefits from the Bike, $10.15 \%$ by factor 2: Enjoyment of the Bike, and $5.89 \%$ by factor 3: Shortcomings of the Bike. Factor correlations were .51 between Factor 1: Academic Benefits from the Bike and Factor 2: Enjoyment of the Bike, .24 between Factor 1: Academic Benefits from the Bike and Factor 3: Shortcomings of the Bike, and .36 for Factor 2: Enjoyment of the Bike and Factor 3: Shortcomings of the Bike. Reliability analysis indicates that the first two factors hold reasonably high internal consistency $(\alpha=.89$ for factor 1 with four items, $\alpha=.86$ for factor 2 with 
five items). However, factor 3 showed lower internal consistency with an $\alpha$ of 64 , partly due to the small number of items included in the scale to present this factor. In addition, the mean scale scores were 2.98 $(S D=1.03, \min =1.00, \max =4.75)$ for factor $1,3.05$ $(S D=1.11, \min =1.20, \max =5.40)$ for factor 2 , and 2.82 $(S D=0.98, \min =1.00, \max =5.00)$ for factor 3 .

\section{DISCUSSION}

The present study found that bicycle workstations in a secondary school setting increased low-intensity physical activity for adolescents compared to traditional chairs. Our findings align with prior research establishing that children's physical activity levels are related to the opportunities they have to engage in exercise (Mahar, 2011), such that when highschool students were given resources to engage in physical activity, they chose to do so via pedalling on the bikes. Other studies have found similar results in placing stand-biased desks in secondary classrooms (Pickens, Benden, Schneider, \& Zhao, 2016; Mehta, Shortz, \& Benden, 2015). Changing the classroom environment so that physical activity may occur has cumulative effects for students. Currently adolescents accrue approximately five minutes of moderate-to-vigorous activity throughout the entire school day (Kohl \& Cook, 2013), with only an estimated 5\% of elementary, middle, and high schools offering PE as a daily option (School Health Policies and Practices Study, 2015). Moreover, less than half (48\%) of high school students participate in physical education classes in a typical school week (CDC, 2015). Thus, the present study offers an additional, feasible venue for adolescents to accrue low-intensity physical activity: the classroom.

The treatment effect on average heart rate was found to be more effective in the first $A B$ pair rather than in the second $\mathrm{AB}$ pair of the withdrawal design. A number of factors could have contributed to this result. For one, students may have been more motivated initially to ride the bike than they were the second time. Research has shown that situational interest, the engaging effect of an activity on individuals (Schiefele, 2009), has the ability to elicit these results (Sun, 2012; Zhu, Chen, \& Parrott, 2014). Situational interest is perceived as a two-state framework (Schiefele, 2009). During the trigger stage, motivation occurs due to the activity's characteristics and the positive emotional outcome associated with it. Yet during the maintaining stage, motivation is dependent on the individual's acknowledgement of the meaningfulness of the activity (Schiefele, 2009). Adolescents are more apt to think about their current, short-term situations rather than focusing on longterm effects such as the health benefits of physical activity (Ionnotti et al., 2013). Perhaps students were more motivated to pedal harder in the first pairing because of the novelty of the bikes and during the second pairing the meaningful, long-term health benefits did not replace initial novelty. Similar findings occurred for a four-week exergaming unit for fourth-grade students. Children's situational interest in exergaming was significantly higher than a standard fitness unit both at the beginning and the end of the intervention; however, interest did decline in both units and at the same rate (Sun, 2012). More research is needed over a longer timeframe to examine what could be a novelty effect for adolescents provided with bicycle workstations.

Female students also had significantly higher average heart rates than male students in the present study. This finding parallels research indicating that boys tend to achieve higher heart rates in team activities (Laurson, Brown, Cullen, \& Dennis, 2008; Nelson et al., 2011), whereas girls achieve higher heart rates in individual physical activities (Kulinna, Martin, Lai, \& Kliber, 2003; Nelson et al., 2011; Sarradel et al., 2011; Yuste, Garcia-Jimenez, \& Garcia-Pellicer, 2015). As a result, the females participating may have been more motivated to pedal the bikes compared to the boys because pedalling was an individual activity and not a team sport.

Worth noting as well is that variability existed across individual students in the classroom. As such, factors such as motivation, self-efficacy, weight, and fitness status may have come into play. Motivation as a factor influencing the variation in physical activity may have depended on the child's personal value placed on exercise, the adolescent's own enjoyment of it, as well as individual interest and competency for riding a bike (Chen, 2013). For example, Peterson et al. (2013) found that parental support was a mediating variable for adolescent physical activity as well as self-efficacy for participating in physical activity such that those children who have parents that value physical activity and their children's participation in it may have children who value it as well and feel more confident in engaging in it. High self-efficacy itself has been linked to increases in physical activity in multiple studies (e.g. Barr-Anderson et al., 2008; Lee, Kuo, Fanaw, Perng, \& Juang, 2012; Rutowski \& Connelly, 2012). In our study, those who had low self-efficacy for riding a bike could have been less likely to pedal or pedal consistently because the teacher did not direct students to do so; however, those with high self-efficacy would probably have pedalled more. Weight status has also been shown to be a factor impacting the motivation children may have to participate in physical activity (St. George, Wilson, Lawman, \& Van Horn, 2013). For example, obese children are not able to participate in exercise for as long a period of time as their more fit peers and when they do participate, it is at a higher heart rate earlier in exercise (Ferns, Wehrmacher, \& Serratto, 2011). 
Alicia Fedewa, Colleen Cornelius, Soyeon Ahn
To this end, those that are obese may find physical activity less motivating because it is uncomfortable, more so than it is for their fitter peers (Stankov, Olds, \& Cargo, 2012). Furthermore, overweight and obese youths may experience verbal bullying by their peers when their extra weight is obvious during strenuous activities (Stankov et al., 2012). This, too, could cause exercise motivation in overweight youths to decrease (Stankov et al., 2012). We did not explore these variables in our present study, but given the variation in physical activity outcomes across adolescents, these questions are important to address in future studies.

The second research question addressed the bicycle workstations' impact on engagement in the classroom. It was hypothesised that on-task engagement of secondary students would improve due to the effects of physical activity; however, the treatment effect was not significant on any of the students' on-task behaviours. Although past research has indicated that physical activity within the classroom enhances on-task behaviour (e.g. Janssen et al., 2014; Mahar et al., 2006; Wadsworth et al., 2015), this was not the case for our findings. This could be due in part to several factors. For one, the structure of the classroom itself was very engaging, with the teacher capitalising on hands-on, small-group activities to maintain the students' attention and to deliver the instruction. Research suggests that high-school classrooms in which the teacher connects to the students, challenges them, and instructs in a lively and engaging manner help adolescents stay on task (Cooper, 2014). Other findings have supported the use of interactive teaching for increased secondary student engagement as well (Godwin et al., 2016; Imeraj et al., 2013). Perhaps, then, in the present classroom environment, students did not have the opportunity for their attention to drift, due to the teacher's method of instruction. Another factor that may have contributed to the lack of significance for on-task behaviour was the demographics of the students participating in the study, as the adolescents were all advanced-placement English students who set academics as a priority (Feld \& Shusterman, 2015; Reed, 2008; Suldo, Shaunessy, Thalji, Michalowski, \& Shaffer, 2009). As such, the participating students valued and saw the importance of the English class and, therefore, were more motivated to focus in class than students in typical classrooms might be. Last, our students were not engaging in moderate-to-vigorous physical activity, which may exert more of an influence on students' on-task behaviour than low-intensity physical activity (Chang, Labban, Gapin, \& Etnier, 2012; Singh, Uijtdewilligen, Twisk, Mechelen, \& Chinapaw, 2012). Future research could explore the differences between low and moderate-to-vigorous activity, when using bicycle workstations, on student behaviour outcomes because this is an area of research that has not been explored.
In response to the third research question regarding the students' acceptance of workstation bikes, the survey assessed three main factors: Academic Benefits from the Bikes, Enjoyment of the Bike, and Shortcomings of the Bike. The most highly-rated factor was Enjoyment of the Bike, indicating that students enjoyed the option of having the bike in the classroom versus sitting in traditional chairs. Their perceived academic benefits from the bike were slightly lower, reflecting that students did not necessarily believe that the bikes helped them learn in the classroom. Shortcomings of the bike was the lowest mean rating, indicating that students found difficulty in riding the bike and engaging in the class simultaneously. Thus, generally speaking, students enjoyed the bikes, but they did not view them as beneficial to their academic performance. These findings were somewhat contradictory to Fedewa, Abel, and Erwin's (2017) study that used FitDesk ${ }^{\circledast}$ bikes to achieve additional physical activity for secondary students but in an alternative school setting. Similarly to the students in present study, Fedewa et al.'s sample expressed enjoyment in using the bikes and also noted shortcomings with the bike, including the comfort of the bike seat and the students' ability to write on the bicycle workstation desk. However, unlike the participants in our present study, the students in Fedewa et al.'s study (2017) commented on the bike's ability to help them "improve focus". Additional studies are needed on larger samples to ascertain whether students perceive bicycle workstations as helpful, detrimental, or neutral to their learning in the classroom. As such, there may be other types of bicycle workstations that are more conducive to helping students accrue additional physical activity while simultaneously completing their academic work. Perhaps other models of bicycle workstations would be more feasible and acceptable in a high-school setting.

\section{LIMITATIONS AND FUTURE RESEARCH}

The small sample size and demographics of the students are limitations to the generalisability of the study. In addition, the inability to capture the students' fitness levels, their motivation to participate in the present study, as well as how often students were actually pedalling while on the bikes are also limitations to be explored in future research because knowledge of these factors would help to understand and contextualise the current findings. Future research may also explore the impact of physical activity within secondary, lecture-based classrooms as well as the relationship between adolescent classroom-based movement and academic achievement in physical activity. Research on elementary students reflects positive benefits aside from simply increasing daily physical activity within the classroom; it also 
improves student motivation, focus, and academic achievement (Carlson et al., 2015; Mulrine, Prater, \& Jenkins, 2008; Whitt-Glover, Ham, \& Yancey, 2011). Therefore, the possibility exists to capture these benefits at the secondary level as well. Finally, because this was a pilot study exploring the feasibility and effect of using bicycle workstations in classrooms, additional variables were not controlled. In the future, perhaps controlling for body mass index, participation in physical activity outside of the school day, gender, and ethnicity may allow findings to be more generalisable. As research in the area of physical activity specifically for adolescents is currently sparse, there is an opportunity to contribute a great deal to the literature currently available (Efrat, 2011; Kohl \& Cook, 2013; Mura et al., 2015).

\section{CONCLUSIONS}

Ultimately, the present study extends current findings in reflecting significance for physical activity within a secondary classroom using FitDesk ${ }^{\circledR}$ bicycle workstations. As adolescence is a time typically when physical activity declines, exploration of additional avenues to embed PA within the school day is warranted. Our findings indicate that secondary students capitalise on options given to exercise and work towards meeting the daily recommendations for physical activity, suggesting possible benefits for their physical and cognitive well-being as well.

\section{REFERENCES}

Babey, S. H., Wu, S., \& Cohen, D. (2014). How can schools help youth increase physical activity? An economic analysis comparing school-based programs. Preventive Medicine, 69, S55-S60.

Bailey, C. G., \& DiPerna, J. C. (2015). Effects of classroom-based Energizers on primary grade students' physical activity levels. Physical Educator, 72, 480 .

Barr-Anderson, D. J., Neumark-Sztainer, D., Lytle, L., Schmitz, K. H., Ward, D. S., Conway, T. L., ...Pate, R. R. (2008). But I like PE: Factors associated with enjoyment of physical education class in middle school girls. Research Quarterly for Exercise and Sport, 79, 18-27.

Barr-Anderson, D.J., AuYoung, M.,Whitt-Glover, M.C., Glenn, B. A., \& Yancey, A. K. (2011). Integration of short bouts of physical activity into organizational routine: A systematic review of the literature. American Journal of Preventive Medicine, 40, 76-93.

Bassett, D. R., Fitzhugh, E. C., Heath, G. W., Erwin, P. C., Frederick, G. M., Wolff, D. L., ...Stout, A. B. (2013). Estimated energy expenditures for schoolbased policies and active living. American Journal of Preventive Medicine, 44, 108-113. http://dx.doi. org/10.1016/j.amepre.2012.10.017

Burkhalter T. M., \& Hillman C. H. (2011). A narrative review of physical activity, nutrition, and obesity to cognition and scholastic performance across the human lifespan. Advances in Nutrition: An International Review Journal, 2, 201S-206S.

Carson, V., Rinaldi, R. L., Torrance, B., Maximova, K., Ball, G. D. C., Majumdar, S. R., ...McCargar, L. (2014). Vigorous physical activity and longitudinal associations with cardiometabolic risk factors in youth. International Journal of Obesity, 38, 16-21.

Carlson, J. A., Engelberg, J. K., Cain, K. L., Conway, T. L., Mignano, A. M., Bonilla, E. A., ...Sallis, J. F. (2015). Implementing classroom physical activity breaks: Associations with student physical activity and classroom behavior. Preventive Medicine, $81,67-72$.

Centers for Disease Control and Prevention. (2011). National diabetes fact sheet: national estimates and general information on diabetes and prediabetes in the United States, 2011. Atlanta, GA: US Department of Health and Human Services, Centers for Disease Control and Prevention, 201.

Centers for Disease Control and Prevention. (2015). Healthy schools. Retrieved from https://www.cdc. gov/healthyschools/index.htm

Centers for Disease Control and Prevention. (2015). How much physical activity do children need? Retrieved from http://www.cdc.gov/physicalactivity/ basics/children/index.html

Centers for Disease Control and Prevention. (2017). Childhood obesity facts. Retrieved from https:// www.cdc.gov/healthyschools/obesity/facts.html

Chang, Y. K., Labban, J. D., Gapin, J. I., \& Etnier, J. L. (2012). The effects of acute exercise on cognitive performance: a meta-analysis. Brain Research, 1453, 87-101.

Chen, A. (2013). Top 10 research questions related to children physical activity motivation. Research Quarterly for Exercise and Sport, 84, 441-447.

Cooper, K. S. (2014). Eliciting engagement in the high school classroom: A mixed-methods examination of teaching practices. American Educational Research Journal, 51, 363-402.

Davis, C. L., Tkacz, J. P., Tomporowski, P. D., \& Bustamante, E. E. (2015). Independent Associations of Organized Physical Activity and Weight Status with Children's Cognitive Functioning: A MatchedPairs Design. Pediatric Exercise Science, 27. doi: http://dx.doi.org/10.1123/pes.2015-0044

Dobbins, M., Husson, H., DeCorby, K., \& LaRocca, R. L. (2013). School-based physical activity programs for promoting physical activity and fitness in children and adolescents aged 6 to 18. Cochrane Database System Review, 2.

Donnelly, J. E., Hillman, C. H., Castelli, D., Etnier, J. L., Lee, S., Tomporowski, P., Lambourne, K., \& Sza-

Bicycle desks 
bo-Reed, A. N. (2016). Physical activity, fitness, cognitive function, and academic achievement in children: A systematic review. Medicine and Science in Sports and Exercise, 48, 1197-1222. doi: 10.1249/MSS.0000000000000901

Donnelly, J. E., \& Lambourne, K. (2011). Classroom-based physical activity, cognition, and academic achievement. Preventive Medicine, 52, S36-S42.

Efrat, M. (2011). The relationship between low-income and minority children's physical activity and academic-related outcomes: a review of the literature. Health Education \& Behavior, 38, 441-451. doi: https://doi.org/10.1177/1090198110375025

Ekelund., U., Luan, J., Sherar, L. B., Esliger, D. W., Griew, P., \& Cooper, A.; International Children's Accelerometry Database (ICAD) Collaborators. (2012). Moderate to vigorous physical activity and sedentary time and cardiometabolic risk factors in children and adolescents. Journal of the American Medical Association, 307, 704-712.

Erwin, H., Fedewa, A., \& Ahn, S. (2013). Student academic performance outcomes of a classroom physical activity intervention: a pilot study. International Electronic Journal of Elementary Education, 5, 109-124.

Fedewa, A. L., Abel, M., \& Erwin, H. E. (2017). The effects of stationary bicycle desks in classrooms on adolescents' physical activity. Journal of Occupational Therapy, Schools, and Early Intervention, 1, 78-89. doi: 10.1080/19411243.2016.1266457

Fedewa, A. L., \& Erwin, H. E. (2011). Stability balls and students with attention and hyperactivity concerns: Implications for on-task and in-seat behavior. American Journal of Occupational Therapy, 65, 393-399. doi: 10.5014/ajot.2011.000554

Feld, L. D., \& Shusterman, A. (2015). Into the pressure cooker: Student stress in college preparatory high schools. Journal of Adolescence, 41, 31-42.

Ferns, S. J., Wehrmacher, W. H., \& Serratto, M. (2011). Effects of obesity and gender on exercise capacity in urban children. Gender Medicine, 8, 224-230.

Godwin, K. E., Almeda, M. V., Seltman, H., Kai, S., Skerbetz, M. D., Baker, R. S., \& Fisher, A. V. (2016) Off-task behavior in elementary school children. Learning and Instruction, 44, 128-143.

Hamilton, K., Warner, L. M., \& Schwarzer, R. (2016). The role of self-efficacy and friend support on adolescent vigorous physical activity. Health $E d-$ ucation and Behavior, 44, 175-181. doi: https://doi org/10.1177/1090198116648266

Have, M., Nielsen, J. H., Gejl, A. K., Ernst, M. T., Fredens, K., Støckel, J. T., ...Kristensen, P. L. (2016). Rationale and design of a randomized controlled trial examining the effect of classroom-based physical activity on math achievement. BMC Public Health, 16, 304.

Hillman, C. H., Buck, S. M., Themanson, J. R., Pontifex, M. B., \& Castelli, D. M. (2009). Aerobic fit- ness and cognitive development: Event-related brain potential and task performance indices of executive control in preadolescent children. Developmental Psychology, 45, 114-129. doi: http:// dx.doi.org/10.1037/a0014437

Hills, A. P., Dengel, D. R., \& Lubans, D. R. (2015). Supporting public health priorities: recommendations for physical education and physical activity promotion in schools. Progress in Cardiovascular Diseases, 57, 368-374.

Howie, E. K., Schatz, J., \& Pate, R. R. (2015). Acute effects of classroom exercise breaks on executive function and math performance: A dose-response study. Research Quarterly for Exercise and Sport, 86, 217-224.

Iannotti, R. J., Kogan, M. D., Janssen, I., \& Boyce, W. F. (2009). Patterns of adolescent physical activity, screen-based media use, and positive and negative health indicators in the U.S. and Canada. Journal of Adolescent Health, 44, 493-499. doi: 10.1016/j.jadohealth.2008.10.142

Imeraj, L., Antrop, I., Sonuga-Barke, E., Deboutte, D., Deschepper, E., Bal, S., \& Roeyers, H. (2013). The impact of instructional context on classroom ontask behavior: A matched comparison of children with ADHD and non-ADHD classmates. Journal of School Psychology, 51, 487-498.

Janssen, M., Chinapaw, M. J. M., Rauh, S. P., Toussaint, H. M., van Mechelen, W., \& Verhagen, E. A. L. M. (2014). A short physical activity break from cognitive tasks increases selective attention in primary school children aged 10-11. Mental Health and Physical Activity, 7, 129-134.

Johnson, K. E., \& Taliaferro, L. A. (2011). Relationships between physical activity and depressive symptoms among middle and older adolescents: A review of the research literature. Journal for Specialists in Pediatric Nursing, 16, 235-251. doi: 10.1111/j.1744-6155.2011.00301.x

Kantomaa, M. T., Stamatakis, E., Kankaanpää, A., Kaakinen, M., Rodriguez, A., Taanila, A., ...Tammelin, T. (2013). Physical activity and obesity mediate the association between childhood motor function and adolescents' academic achievement. Proceedings of the National Academy of Sciences, 110, 1917-1922. doi: www.pnas.org/cgi/doi/10.1073/pnas. 1214574110

Kibbe, D. L., Hackett, J., Hurley, M., McFarland, A., Schubert, K. G., Schultz, A., \& Harris, S. (2011). Ten Years of TAKE 10!: Integrating physical activity with academic concepts in elementary school classrooms. Preventive Medicine, 52, 43-50. doi: 10.1016/j.ypmed.2011.01.025

Kohl III, H. W., \& Cook, H. D. (eds.). (2013). Educating the student body: Taking physical activity and physical education to school. Washington (DC): National Academies Press.

Kriemler, S., Meyer, U., Martin, E., van Sluijs, E. M. F., Andersen, L. B., \& Martin, B. W. (2011). Effect of 
school-based interventions on physical activity and fitness in children and adolescents: a review of reviews and systematic update. British Journal of Sports Medicine, 45, 923-930.

Kulinna, P. H., Martin, J., Lai, Q., Kliber, A., \& Reed, B. (2003). Student physical activity patterns: Grade, gender, and activity influences. Journal of Teaching in Physical Education, 22, 298-310.

Laurson, K. R., Brown, D. D., Dennis, K. K., \& Cullen, R. W. (2008). Heart rates of high school physical education students during team sports, individual sports, and fitness activities. Research Quarterly for Exercise and Sport, 79, 85-91.

Lee, L. L., Kuo, Y. C., Fanaw, D., Perng, S. J., \& Juang, I. F. (2012). The effect of an intervention combining self-efficacy theory and pedometers on promoting physical activity among adolescents. Journal of Clinical Nursing, 21, 914-922.

Ma, J. K., Le Mare, L., \& Gurd, B. J. (2014). Four minutes of in-class high-intensity interval activity improves selective attention in 9- to 11-year olds. Applied Physiology, Nutrition, and Metabolism, 40, 238-244. doi: dx.doi.org/10.1139/apnm-2014-0309

Mahar, M. T., Murphy, S. K., Rowe, D. A., Golden, J., Shields, A. T., \& Raedeke, T. D. (2006). Effects of a classroom-based program on physical activity and on-task behavior. Medicine and Science in Sports and Exercise, 38, 2086. doi: 10.1249/01. mss.0000235359.16685.a3

Mahar, M. T. (2011). Impact of short bouts of physical activity on attention-to-task in elementary school children. Preventive Medicine, 52, 60-64. doi: 10.1016/j.ypm

Mehta, R. K., Shortz, A. E., \& Benden, M. E. (2015). Standing up for learning: A pilot investigation on the neurocognitive benefits of stand-biased school desks. International Journal of Environmental Research and Public Health, 13, 59. doi: 10.3390/ ijerph 13010059

Mitchell, J. A., Pate, R. R., Dowda, M., Mattocks, C., Riddoch, C., Ness, A. R., \& Blair, S. N. (2012). A prospective study of sedentary behavior in a large cohort of youth. Medicine and Science in Sports and Exercise, 44, 1081. doi: 10.1249/MSS.0b013e3182446c65

Mulrine, C. F., Prater, M. A., \& Jenkins, A. (2008). The active classroom: Supporting students with attention deficit hyperactivity disorder through exercise. Teaching Exceptional Children, 40, 16.

Mura, G., Vellante, M., Egidio Nardi, A., Machado, S., \& Giovanni Carta, M. (2015). Effects of schoolbased physical activity interventions on cognition and academic achievement: a systematic review. CNS and Neurological Disorders-Drug Targets (Formerly Current Drug Targets-CNS and Neurological Disorders), 14, 1194-1208.

National Center for Education Statistics. (2016). Back to school statistics. Retrieved from http:// nces.ed.gov/fastfacts/display.asp?id=372
Nelson, L., Guess, W., Olson, T., Buckwalter, J., Evans, M., \& Morris, M. (2011). Heart rates of elementary physical education students during the dancing classrooms program. Research Quarterly for Exercise and Sport, 82, 256-263.

Peterson, M. S., Lawman, H. G., Wilson, D. K., Fairchild, A., \& Van Horn, M. L. (2013). The association of self-efficacy and parent social support on physical activity in male and female adolescents. Health Psychology, 32, 666.

Pickens, A. W., Benden, M. E., Schneider, D. E., \& Zhao, H. (2016). Use of Stand-Biased Desks to Reduce Sedentary Time in High School Students: A Pilot Study. International Journal of Child Health and Nutrition, 5, 75-78. doi: 10.6000/19294247.2016.05.02.4

Pontifex, M. B., Scudder, M. R., Drollette, E. S., \& Hillman, C. H. (2012). Fit and vigilant: the relationship between poorer aerobic fitness and failures in sustained attention during preadolescence. Neuropsychology, 26, 407-413. doi: 10.1037/a0028795

Rapp, J. T., Colby-Dirksen, A. M., Michalski, D. N., Carroll, R. A., \& Lindenberg, A. M. (2008). Detecting changes in simulated events using partial-interval recording and momentary timesampling. Behavioral Interventions, 23, 237-269. doi: http:// dx.doi.org/10.1002/bin.269

Rasberry, C. N., Lee, S. M., Robin, L., Laris, B. A., Russell, L. A., Coyle, K. K., \& Nihiser, A. J. (2011). The association between school-based physical activity, including physical education, and academic performance: a systematic review of the literature. Preventive Medicine, 52, 10-20.

Reed, J. (2008). Shifting up: A look at advanced mathematics classes in tracked schools. The High School Journal, 91, 45-58.

Rutkowski, E. M., \& Connelly, C. D. (2012). Self-efficacy and physical activity in adolescent and parent dyads. Journal for Specialists in Pediatric Nursing, 17, 51-60.

Salvy, S. J., Roemmich, J. N., Bowker, J.C., Romero, N. D., Stadler, P. J., \& Epstein, L. H. (2009). Effect of peers and friends on youth physical activity and motivation to be physically active. Journal of Pediatric Psychology, 34, 217-225. doi: https://doi.org /10.1093/jpepsy/jsn071

Sarradel, J., Generelo, E., Zaragoza, J., Julián, J. A., Abarca-Sos, A., Murillo, B., \& Aibar, A. (2011). Gender differences in heart rate responses to different types of physical activity in physical education classes. European Journal of Human Movement, 26, 65-76.

School Health Policies and Practices Study 2014. (2015). Center for Disease Control. Retrieved from https://www.cdc.gov/healthyyouth/data/shpps/ pdf/shpps-508-final_101315.pdf

Schiefele, U. (2009). Situational and individual interest. In K. R. Wentzel \& A. Wigfield (eds.), Hand- 
Alicia Fedewa, Colleen Cornelius, Soyeon Ahn book of motivation at school (pp. 197-222). New York: Routledge.

Shin, Y. S., \& So, W. Y. (2012). Association between physical inactivity and academic record in Korean adolescents. Iranian Journal of Public Health, 41, 36.

Singh, A., Uijtdewilligen, L., Twisk, J. W., Van Mechelen, W., \& Chinapaw, M. J. (2012). Physical activity and performance at school: a systematic review of the literature including a methodological quality assessment. Archives of Pediatrics and Adolescent Medicine, 166, 49-55.

St. George, S. M. S., Wilson, D. K., Lawman, H. G., \& Van Horn, M. L. (2013). Weight status as a moderator of the relationship between motivation, emotional social support, and physical activity in underserved adolescents. Journal of Pediatric Psychology, 38, 387-397.

Stankov, I., Olds, T., \& Cargo, M. (2012). Overweight and obese adolescents: what turns them off physical activity? International Journal of Behavioral Nutrition and Physical Activity, 9, 53.

Suldo, S. M., Shaunessy, E., Thalji, A., Michalowski, J., \& Shaffer, E. (2009). Sources of stress for students in high school college preparatory and general education programs: Group differences and associations with adjustment. Adolescence, 44, 925.

Sun, H. (2012). Exergaming impact on physical activity and interest in elementary school children. $R e$ search Quarterly for Exercise and Sport, 83, 212-220.

Tarp, J., Domazet, S. L., Froberg, K., Hillman, C. H., Andersen, L. B., \& Bugge, A. (2016). Effectiveness of a School-Based Physical Activity Intervention on Cognitive Performance in Danish Adolescents: LCoMotion Learning, Cognition and Motion A Cluster Randomized Controlled Trial. PloS One, 11, e0158087.

Turley, K. R. (1997). Cardiovascular responses to exercise in children. Sports Medicine, 24, 241-257.

Verburgh, L., Königs, M., Scherder, E. J., \& Oosterlaan, J. (2013). Physical exercise and executive functions in preadolescent children, adolescents and young adults: A meta-analysis. British Journal of Sports Medicine, 48, 973-979.

Webster, E. K., Wadsworth, D. D., \& Robinson, L. E. (2015). Preschoolers' Time On-Task and Physical Activity During a Classroom Activity Break. Pediatric Exercise Science, 27, 160-167.

Whitt-Glover, M. C., Ham, S. A., \& Yancey, A. K. (2011). Instant Recess ${ }^{\circledR}$ : a practical tool for increasing physical activity during the school day. Progress in Community Health Partnerships: Research, Education, and Action, 5, 289-297.

World Health Organization. (2011). Global Strategy on Diet, Physical Activity and Health. Retrieved from http://www.who.int/dietphysicalactivity/ childhood/en/

Yuste, J. L., García-Jiménez, J. V., \& García-Pellicer, J. J. (2015). Intensity of physical education classes in adolescents. Revista Internacional de Medicina y Ciencias de la Actividad Fisica y del Deporte, 15, 309-323.

Zhu, X., Chen, S., \& Parrott, J. (2014). Adolescents' interest and performances in aerobic fitness testing. Journal of Teaching in Physical Education, 33, $53-67$. 